\title{
Capacitação Gerencial nas Incubadoras de Base Tecnológica: proposição de um modelo matricial de avaliação
}

\author{
Wescley Silva Xavier ${ }^{1}$ \\ Guilherme Silveira Martins ${ }^{2}$ \\ Afonso Augusto Teixeira de Freitas de Carvalho Lima ${ }^{3}$
}

\section{Resumo}

Este trabalho tem como objetivo a proposição de uma ferramenta de avaliação de programas de capacitação gerencial de Incubadoras de Empresas. Tal ferramenta foi desenvolvida a partir de um estudo em 14 Incubadoras e 115 empreendimentos nascentes de base tecnológica. A avaliação é realizada nas tradicionais áreas funcionais da Administração (i.e. Marketing, Recursos Humanos, Finanças e Operações) em duas dimensões: (a) uma compara o domínio que o empresário julga possuir dos fundamentos de cada disciplina da Administração e a importância que esses fundamentos têm para o seu negócio; (b) a outra dimensão compara essa importância atribuída pelo empresário com o quanto o fundamento foi contemplado no programa de capacitação gerencial oferecido pela incubadora. Com isso, é possível avaliar, respectivamente, as lacunas de conhecimento que os empresários julgam possuir e quais pontos podem ser mais bem explorados pela incubadora nos treinamentos gerenciais. O estudo de campo revelou que os fundamentos de Marketing e Finanças são vistos como mais importantes pelos empresários e mais contemplados nos programas de capacitação. Ademais, verificou-se a existência de lacunas entre importância atribuída pelos empresários $e$ a efetividade da incubadora em alguns elementos, o que sugere a necessidade de reavaliar os programas de capacitação gerencial.

Palavras-chave: Capacitação gerencial. Incubadora de base tecnológica. Modelode avaliação.

\footnotetext{
${ }^{1}$ Doutorando e Mestre pelo Centro de Pós-Graduação e Pesquisa em Administração da Universidade Federal de Minas Gerais - CEPEAD/ UFMG. End.: Av. Antônio Carlos, 6627 / sala 4012 - Pampulha, Belo Horizonte - MG. CEP: 31270-901 - Brasil. E-mail: wescleysxavier@yahoo.com.br.

${ }^{2}$ Doutorando e Mestre pela Escola de Administração de Empresas de São Paulo - EAESP, Fundação Getúlio Vargas - FGV. End.: Av. 9 de Julho, 2029 - Bela Vista, São Paulo -SP. CEP: 01313-902 - Brasil. E-mail: mr.gsmartins@gmail.com.

${ }^{3}$ Doutor em Engenharia de Produção pela Universidade Federal de Santa Catarina - UFSC. Professor Associado do Departamento de Administração da Universidade Federal de Viçosa - UFV. Endereço: Av. P.H. Rolfs, s/n - Campus Universitário, Viçosa - MG. CEP: $36570-000$ -Brasil.E-mail:afonsoli@ufv.br.

Artigo recebido em: 11/02/2008. Aceito em: 25/10/2009. Membro do Corpo Editorial Científico responsável pelo processo editorial: Martinho Isnard Ribeiro de Almeida.
}

Esta obra está sob a Licença Creative Commons Atribuição-Uso. 


\section{Introdução}

Incubadoras de empresas são ambientes apropriados para abrigar empreendimentos nascentes e ampará-los, de forma a contribuir com a consolidação e o crescimento das empresas e aumentar suas chances de sobrevivência no mercado. Os empreendedores veem na incubadora uma boa oportunidade de iniciar seu negócio em um ambiente favorável, por terem à disposição auxílionos momentos iniciais, em que os empreendimentos mais carecem de estruturação. As incubadoras em geral oferecem aos empreendedores instalações físicas, suporte técnico e gerencial no início e durante as etapas de desenvolvimento do negócio.

Dentre as modalidades de incubadoras existentes, destaca-se a de Incubação de Base Tecnológica, mais comum no Brasil, com 48\% das 393 incubadoras existentes em 2007 (ANPROTEC, 2008). São incubadoras que abrigam empreendimentos para as quais o conhecimento é o principal insumo, e que comercializam produtos com alto valor agregado. Valério (2006) afiança que atividades essenciais para a gestão de empresas da área tecnológica são, geralmente, desempenhadas por pessoal técnico, com pouca ou nenhuma formação gerencial. Assim, as novas empresas apresentam carência de conhecimentos sobre, por exemplo, questões mercadológicas, aspectos legais e financeiros e, inclusive, sobre possíveis parcerias com órgãos governamentais e outras fontes potenciais de recursos.

Assim, a capacitação gerencial é um elemento do processo de incubação que tem se destacado devido à importância de sua configuração na formação do empreendedor. Capacitar gerencialmente um empresário pode significar potencializar ideias sob a perspectiva mercadológica, fazendo com que a capacidade técnica dos sócios seja transformada em ofertas. Dessa forma, um dos grandes desafios das incubadoras é atender necessidades dos empresários e alocar recursos muitas vezes escassos em cursos e treinamentos que venham suprir lacunas detectadas na formação gerencial. Sob essa perspectiva, parece ser relevante que as incubadoras conheçam quais são as reais necessidades dos empresários e em quais áreas há maior carência.

Com base no exposto, este trabalho tem como objetivo a proposição de uma ferramenta de avaliação de programas de capacitação gerencial de Incubadoras de Empresas a partir do desenvolvimento de um estudo em 14 Incubadoras e 115 empreendimentos nascentes de base tecnológica. A pesquisa avaliou os programas de incubação das incubadoras estudadas com 
base na percepção dos empresários em relação à importância dos fundamentos da Administração, à sua presença na capacitação gerencial oferecida pela incubadora e ao domínio que julgava possuir.

O artigo está estruturado em cincopartes: em primeiro lugar esta introdução;na segunda seção são apresentados os fundamentos teóricos e empíricos do trabalho; na terceira seção são explicitados os procedimentos metodológicos adotados antes e durante a execução da pesquisa;a quarta seção traz a apresentação e discussão dos resultados;na quinta e última seção estão os comentários finais e as recomendações para futuros estudos sobre o tema.

\section{Referencial Teórico-Empírico}

\subsection{Incubadoras de Base Tecnológica}

A ANPROTEC (Associação Nacional de Entidades Promotoras de Empreendimentos de Tecnologia Avançada - BRASIL, 2002) e a NBIA (National Business IncubatorAssociation - EUA, 2006) definem incubadoras como ambientes especialmente planejados para acolher micro e pequenas empresas nascentes, bem como aquelas que buscam a modernização de suas atividades, de forma a transformar ideias em produtos, processos e/ou serviços. Nelas, o processo de incubação pretende conferir às empresas condições favoráveis para detectar tendências, incorporar novidades e acompanhar as mudanças de mercado, principalmente atuando como interface entre o setor acadêmico e produtivo.

Grimaldi e Grandi (2005) salientam que a incubadora é um meio eficaz de associar tecnologia, capital e know-how, a fim de alavancar o talento empresarial, acelerar o desenvolvimento de novas empresas e, assim, acelerar a exploração de tecnologias.

Hackett e Dilts (2004) salientam que, quando se discute o tema "incubadoras", é importante atentar para cada uma delas em sua totalidade, não simplesmente como um espaço empresarial compartilhado cuja principal característica é a infraestrutura. A incubadora é também uma rede de indivíduos e organizações, incluindo toda a equipe de gerência, seu conselho administrativo, clientes das empresas e empresários, universidade e membros da comunidade universitária, contatos industriais e demais profissionais, como 
consultores, investidores de risco e voluntários. Diversos autores asseveram que essa rede de relacionamentos pode gerar boas oportunidades aos empresários vinculados à incubadora (BAKOUROS et al., 2002; BOLLINGTOFT; ULHOI, 2005; CHAN; LAU, 2005).

Já O’Neal (2005) chama atenção para a importância de o que define como serviços de assistência empresarial, referindo-se às ações desenvolvidas pelas incubadoras no apoio ao desenvolvimento das empresas. Segundo o autor, são esses serviços que diferenciam uma incubadora de outra. Dessa forma, a eficácia do serviço prestado pela incubadora aos empresários incubados é considerada fator decisivo para o sucesso da incubadora, que pode ser entendido como a formação de empresas mais longevas e bemsucedidas.

Para uma melhor contextualização das incubadoras de base tecnológica, parece interessante entender melhor as características das empresas nelas incubadas. Na próxima seção foram abordados as definições, as características e os principais problemas enfrentados pelas empresas de base tecnológica.

\subsection{Empresas de Base Tecnológica}

Segundo a ANPROTEC (2002), uma empresa de base tecnológica (EBT) é um empreendimento que fundamenta sua atividade produtiva no desenvolvimento de novos produtos ou processos, baseado na aplicação sistemática de conhecimentos científicos e tecnológicos e utilização de técnicas avançadas ou pioneiras. Lemos (1998) ressalta que, para o Ministério de Ciência e Tecnologia (MCT), as EBTs são aquelas empresas que apresentam o conhecimento científico-tecnológico como seu principal insumo de produção e que se relacionam intensamente entre si e com universidades ou institutos de pesquisa, fazendo uso de recursos humanos, laboratórios e equipamentos pertencentes a essas instituições.

Santos e Pereira (1989) apresentam definição semelhante. Conceituam tais empresas como aquelas que envolvem em seu corpo profissional pesquisadores com alta capacitação técnica em suas respectivas áreas de competência, cuja tecnologia agregada aos produtos tem peso relativamente mais importante no seu custo final do que a matéria-prima, e que investem constantemente em Pesquisa e Desenvolvimento (P\&D), visando à contínua atualização tecnológica de sua linha de produtos. 
Para Maculan (1996a), as empresas de base tecnológica correspondem a empreendimentos que incorporam em seu processo produtivo elevado grau de conhecimento científico e de domínio de técnicas complexas. Desse modo, podem gerar produtos já existentes com redução de custos e de tempo de produção, ou produtos inovadores que os processos usuais não conseguem trazer ao mercado.

Myllyniemiet al. (1990) afirmam que as empresas de base tecnológica têm um significante papel no desenvolvimento de novos produtos e na transferência de tecnologia dos centros de pesquisa e universidades para o comércio e a indústria de seus países. Afirmam também que muitos países têm reconhecido a importância das empresas de base tecnológica. Assim, esses países estão investindo em pesquisas para promover esse tipo de empresa $e$ também promovem o empreendedorismo acadêmico.

A maioria das empresas de base tecnológica permanece pequena, embora tenham notório potencial de crescimento. No entanto, essas companhias dão grande contribuição à economia. Isso sugere que seria necessário tratálas com mais seriedade para encorajá-las e ajudá-las a crescer (MYLLYNIEMI, et al., 1990).

\subsection{Capacitação Gerencial}

De maneira geral, a sobrevivência das empresas de base tecnológica depende de sua capacidade gerencial e organizacional, e da decorrente capacidade de estabelecer parcerias (MACULAN, 2004). No entanto, nas pequenas EBTs, o processo de planejamento e desenvolvimento geralmente é liderado por pessoas de áreas técnicas, nas quais a formação gerencial é, frequentemente, inexpressiva (VALÉRIO, 2006). Se as incubadoras são ambientes facilitadores do processo de aprendizagem, inclusive gerencial (MACULAN, 2004), o processo de incubação tende a ampliar o potencial de sucesso das empresas.

$\mathrm{Na}$ infraestrutura que as incubadoras oferecem para incubação, esperase encontrar os instrumentos necessários para dinamizar os recursos disponibilizados para as empresas de base tecnológica, criando um ambiente favorável para o processo de aprendizado gerencial dos novos empreendedores (SILVA, 2000).

Aranha et al. (2002) comentam que as incubadoras de empresas, sobretudo as ligadas a universidades, são ambientes híbridos nos quais as di- 
mensões científica e empresarial se encontram. Em geral, funcionam como um elo entre o conhecimento acadêmico e a aplicação empresarial e possuem uma ampla rede de interações com outras instituições que favorece o ambiente de aprendizado organizacional para as pequenas EBTs.A esse respeito, Baêta (1997, p. 86) afirmou que "[...] a proposta de Parques Tecnológicos e Incubadoras de Empresas parece condizente com a construção de uma capacidade gerencial capaz de interferir no processo de aprendizagem [...]".

A autora reforça a posição afirmando que a atuação das incubadoras pode auxiliar as pequenas EBTs no processo de aprendizagem na medida em que, além das parcerias formais, há uma série de intercâmbios com outras entidades para uso de laboratórios, troca de informações e uso de espaços que ocorrem de modo informal. Os empresários, por serem também, professores e pesquisadores da Universidade ou Centro de Pesquisa, ou egressos daquelas instituições, têm facilidade de acesso a esses espaços, além do relacionamento com ex-colegas. Isso faz com que se desenvolva uma aprendizagem interativa no ambiente das incubadoras.

Segundo Maculan (1996b), um elemento importante da incubadora é a sua atuação como intermediária no estabelecimento das ligações externas com agências governamentais e na busca de informações gerenciais, tecnológicas, legais e financeiras. Assim, são instituições que possuem relações privilegiadas com entidades como o Serviço Brasileiro de Apoio às Micro e Pequenas Empresas - SEBRAE, o que a permite proporcionar formação em gestão empresarial, geralmente ausente nos empreendedores. Funciona também como uma garantia informal da qualidade dos serviços ou produtos oferecidos pelas empresas, pois o nome da universidade ou instituição de pesquisa responsável pela gestão da incubadora ajuda as empresas na criação de uma imagem externa positiva de seriedade, qualidade e competência.

\section{Procedimentos Metodológicos}

Para atingir os objetivos declarados deste trabalho, realizou-se uma pesquisa exploratória e descritiva. Exploratória devido ao fato de se ter, relativamente, pouco conhecimento acumulado e sistematizado a respeito do processo de incubação, especialmente no que tange à incubação de empresas de base tecnológica. Como ressaltam Vedovello e Figueiredo (2005), o que há na literatura sobre incubadoras são relatos variados de experiências. 
Para Selltizet al.(1967), uma pesquisa exploratória é aquela que tem como objetivo proporcionar maior familiaridade com o problema, com vistas a torná-lo mais explícito, como é o presente caso, ou a construir hipóteses.

A pesquisa também teve características descritivas em função do objetivo de identificar, compreender e descrever alguns elementos inerentes ao processo de incubação. As unidades de análise foram as empresas ligadas a Incubadoras de Base Tecnológica do Estado de Minas Gerais, somando 115 empresas - 64\% do total - (RMI, 2005) em 16 incubadoras distribuídas em dez diferentes cidades, sendo definida a partir de uma amostra não probabilística por acessibilidade.

Os dados foram coletados a partir de um questionário estruturado que buscouconhecer a percepção dos empresários acerca da capacitação gerencial que haviam recebido da incubadora nas quatro grandes áreas funcionais da Administração, Marketing, Recursos Humanos, Finanças e Operações (KWASNICKA, 2004). Essas áreas foram decompostas em seus elementos fundamentais (doravante denominados fundamentos), de acordo com alguns autores considerados relevantesem cada área. Recursos Humanos: Araújo (2006); Chiavenato (1999); Lacombe (2006); Souza (2002). Marketing: Dalrymple (2003); Czinkota (2002); Kotler e Armstrong (2008); Kotler e Keller (2005); Urdan eUrdan (2006). Finanças: Assaf Neto (2003); Gitman (2001); Ross et al. (2002); Weston e Brigham (2004). Operações: Gaither; Frazier (2001); Corrêa; Corrêa (2007); Slack et al. (2002); Stevenson (2001).

Para isso, e a partir desses fundamentos, os empresários foram convidados a avaliá-los sob três perspectivas: importância do fundamento, presença na capacitação gerencial oferecida pela incubadora e domínio do fundamento. Para mensurar a avaliação dos empresários, foi utilizada uma escala linear não estruturada composta de duas âncoras nas extremidades. A vantagem da utilização da escala linear não estruturada é a ausência de um valor numérico ao longo da escala associado com a resposta, ou seja, a escala não contém valores intermediários, de forma que a única referência para os respondentes seja o espaço horizontal e os diferenciais semânticos presentes nas extremidades. Além disso, há que se ressaltar que o limitado uso de palavras minimiza as possíveis tendências do respondente em evitar ou preferir determinados números ou expressões (STONE; SIDEL, 1993). Como não existem intervalos intermediários nesse tipo de escala, os entrevistados são convidados a marcar um traço perpendicular à reta, demarcando seu posicionamento ou concordância pela percepção de distância ou proximi- 
dade das extremidades. Após, mede-se a distância desse traço até a origem em escala de dez, sendo essa considerada a nota atribuída pelo entrevistado.

Quanto aos valores mensurados na escala,eles foram tabulados e após o cálculo das médias de cada fundamento, os dados foram agrupados em duas matrizes de dispersão (XY). As duas matrizes apresentadas na Figura 1 permitiram identificar as relações importância de cada fundamento versuspresença na capacitação, e importância versusdomínio do fundamento. Os quadrantes de 1 a 4 na matriz A permitiram identificar se o grau de importância atribuída a um fundamento tem equivalente participação na capacitação gerencial. Já com os quadrantes de 5 a 8 na matriz $\mathrm{B}$, foi possível identificar se os empresários têm domínio equivalente à importância atribuída a cada fundamento.

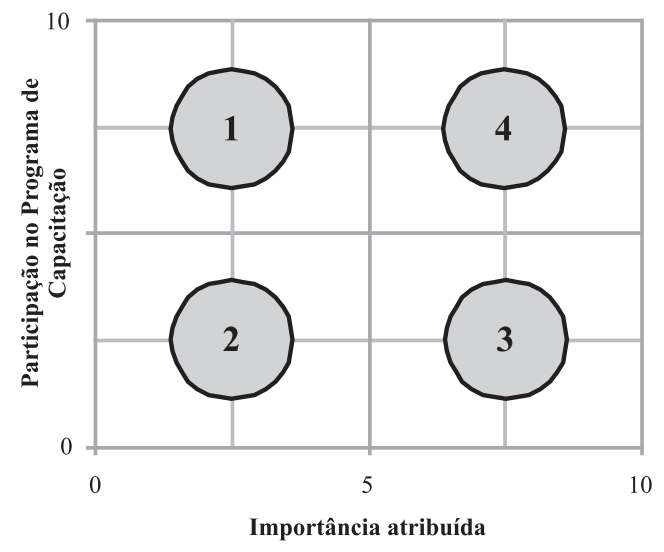

(A)

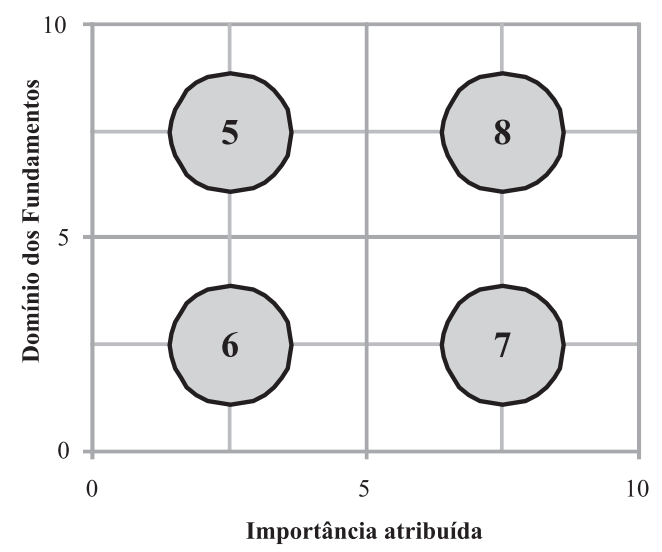

(B)

Figura 1: Matrizes-modelo utilizadas na avaliação dos programas de capacitação gerencial Fonte: Elaborada pelos autores

Adicionalmente, foram calculados e avaliados os índicesque apontam a relação de equilíbrio dos fundamentos, tanto para importância do fundamento versus presença na capacitação quanto para importância versusdomínio do fundamento. No primeiro caso, um valor negativo resultante da subtração da importância do fundamento pela sua presença na capacitação indica uma lacuna a ser suprida pelas incubadoras no processo de capacitação gerencial. No segundo caso, um valor negativo resultante da subtração do domínio do fundamento pela sua importância indica uma lacuna a ser suprida pelos empresários, evidentemente, assistidos pelas incuba- 
doras. Analogamente, os valores positivos, quando encontrados, indicam o grau de sucesso do processo de capacitação gerencial tanto para as incubadoras, no primeiro caso, quanto para os empresários, no segundo caso.

\section{Apresentação e Discussão dos Resultados}

Com base nos objetivos, os resultados foramorganizados pelas áreas de funcionais. Em cada área são apresentadas duas matrizes de avaliação. A primeira visa identificar a efetividade dos programas de capacitação gerencial, considerando a importância atribuída pelos entrevistados e a presença na capacitação oferecida pelas incubadoras. A segunda visa a identificar o nível de conhecimento gerencial dos entrevistados para aqueles fundamentos que eles consideram relevantes.

Em complemento, a cada área funcional são apresentadas tabelas que indicam lacunas a serem sanadas, tanto pelas incubadoras, no caso do programa de capacitação, quanto pelos empresários, em termos de conhecimento sobre os fundamentos. Dessa forma, as tabelas proporcionam uma leitura não apenas para áreas em que a capacitação pode ser ponto crítico, mas também para elementos dentro de uma mesma área de gestão.

\subsection{Fundamentos de Marketing}

A avaliação dos empresários em relação aos fundamentos de Marketing indica que eles são considerados de grande importância e que há lacunas na participação dos mesmos nos respectivos programas e ainda no próprio conhecimento gerencial dos empresários. Conforme a Figura 2, a importância atribuída ficou no primeiro quartil para todos os fundamentos (notas médias entre 7,5 e 10).

Quanto à participação dos fundamentos nos programas de capacitação (Figura 2A), verificou-se que foi considerada entre média e alta (notas entre 5 e 7,5). Apenas em Dimensão estratégica do Marketing ficou acima da média, e, ao se comparar com a importância atribuída aos fundamentos da área, é possível a identificação de lacunas a serem sanadas. 


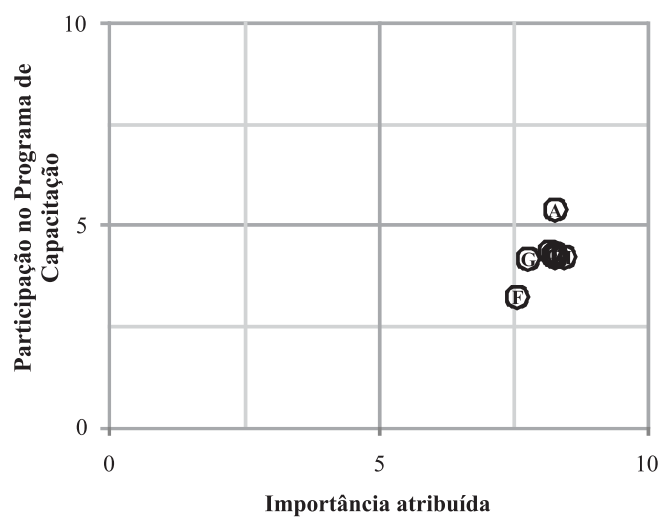

(A)

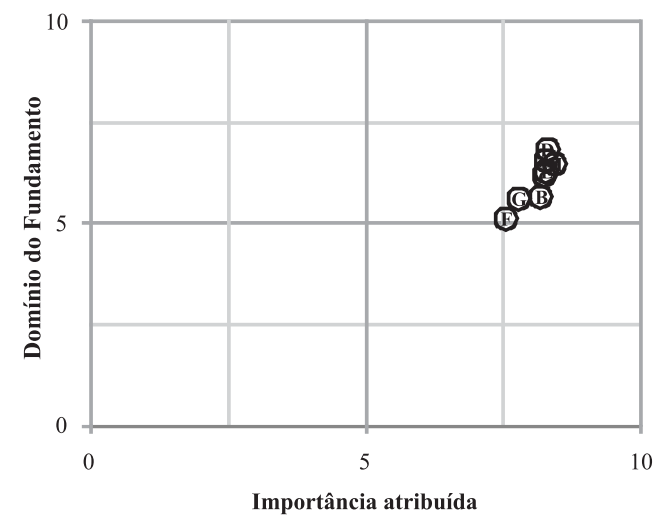

(B)

\section{Legenda:}
A Dimensão Estratégica
E Estratégias de Preço
B Gerenciamento da base de dados dos clientes
F Estratégias de Distribuição
C Segmentação e posicionamento
G Estratégias de Promoção
D Estratégias de Produtos/Serviços
H Atração e Retenção de Clientes

Figura 2: Avaliação da capacitação gerencial nos fundamentos de Marketing Fonte: Dados da pesquisa

Dentre os fundamentos, os empresários atribuíram menor importância relativa a Estratégias de Distribuição e a Estratégias de Promoção, sendo a importância dos demais fundamentos relativamente homogênea. Abaixa importância relativa atribuída aos dois fundamentos anteriormente citados pode ser explicada, em parte, pela também baixa capacidade de produção e comercialização das empresas, uma vez que grande parte da oferta é produzida já com mercado prospectado ou sob encomenda. Por operar no limite de sua capacidade produtiva, as empresas investem menos esforços na prospecçãode uma nova demanda, uma vez que a capacidade produtiva não permitiria o atendimento, característica comum a empresas nascentes ou em fases iniciais.

Quanto ao domínio que os empresários declararam ter dos fundamentos, foi maior em Segmentação e Posicionamento e Estratégias de Promoção, mesmo tendo sido este último fundamento considerado de baixa importância relativa. A Figura $2 \mathrm{~b}$ também indica que é relativamente menor o domínio em Estratégias de Preço e Atração e Retenção de Clientes, desvelando real necessidade dos empresários em termos de proficiência nesses fundamentos, uma vez que ambos foram considerados de grande importância. 
Outro ponto observado foi a presença dos fundamentos na capacitação gerencial, ou seja, o quanto a incubadora ofereceu para os empresários. Com exceção do fundamento Dimensão Estratégica, em todos os fundamentos, a participação da incubadora na capacitação foi considerada entre média e baixa, variando entre 2,5 e 5 .

Em termos individuais, os fundamentos Estratégias de Distribuição e Estratégias de Promoção, considerados os de menor importância dentre os demais, também foram avaliados como os menos presentes na capacitação. Esse cenário poderia indicar uma aparente situação de equilíbrio em relação a esses fundamentos, uma vez que, apesar de menos presentes na capacitação gerencial, são considerados os de menor importância. Porém, situações de equilíbrio ou discrepância podem ser observadas entre a avaliação de importância e domínio dos fundamentos (sob a perspectiva das empresas), e importância e presença na capacitação (sob a perspectiva das incubadoras).

Assim, uma situação favorável ao empresário se caracteriza quando o resultado da subtração entre importância e domínio for nulo ou negativo, indicando domínio compatível ou superior à importância atribuída a um fundamento. Da mesma forma é a análise sob perspectiva da incubadora, sendo favorável quando o resultado da subtração entre importância e presença na capacitação for nulo ou negativo, indicando presença na capacitação compatível ou superior à importância atribuída a um fundamento. Esses cálculos encontram-se representados na Tabela 1.

Tabela 1: Relação de equilíbrio nos fundamentos de Marketing

\begin{tabular}{|l|c|c|}
\hline \multirow{2}{*}{ Fundamento } & \multicolumn{2}{c|}{ Equilíbrio } \\
\cline { 2 - 3 } & $\begin{array}{c}\text { Importância } \\
\text { versus Domínio }\end{array}$ & $\begin{array}{c}\text { Importância versus } \\
\text { Capacitação }\end{array}$ \\
\hline Dimensão Estratégica & 2,70 & 3,16 \\
\hline Gerenciamento da base de dados dos clientes & 2,11 & 4,11 \\
\hline Segmentação e Posicionamento & 1,41 & 4,21 \\
\hline Estratégias de Produtos/Serviços & 2,07 & 4,25 \\
\hline Estratégias de Preço & $\underline{3,23}$ & $\underline{4,31}$ \\
\hline Estratégias de Distribuição & 1,95 & $\underline{4,42}$ \\
\hline Estratégias de Promoção & 1,26 & 3,72 \\
\hline Atração e Retenção de Clientes & $\underline{3,17}$ & $\underline{4,48}$ \\
\hline Média & $\mathbf{2 , 2 4}$ & $\mathbf{4 , 0 8}$ \\
\hline
\end{tabular}

Fonte: Dados da pesquisa 
Com base na Tabela 1, verificou-se que em todos os fundamentos de marketing as situações são desfavoráveis tanto para as empresas quanto para as incubadoras, sendo pontos de carências os fundamentos com valores em destaque. Dessa forma, ressalta-se a necessidade de as incubadoras incrementarem os programas de capacitação gerencial nos pontos que apresentam notas significativamente negativas, bem como de os empresários buscarem maior conhecimento quando os resultados negativos se intensificam. Vale ressaltar que os fundamentos Atração e Retenção de Clientes e Estratégias de Preço podem ser considerados pontos críticos, uma vez que tanto a proficiência dos empresários quanto a participação da incubadora são mais deficientes nesses fundamentos, caracterizando-se ainda mais como pontos demandantes de atenção por parte dos programas de capacitação gerencial.

\subsection{Fundamentos de Recursos Humanos - RH}

A avaliação dos entrevistados, em relação aos fundamentos deRH, indica que elessão considerados importantes, com notas médiasdistribuídas entre os dois primeiros quartis da matriz de avaliação (Figura 3). Já em relação ao domínio nos mesmos fundamentos, foi considerado entre médio e alto - avaliações entre 5 e 7,5. Dentre os fundamentos, os empresários atribuíram menor importância relativa (entre 5 e 7,5) ao Desenho de Cargos e Programas de Manutenção, sendo a importância dos demais fundamentos avaliada entre 7,5 e 10. Ponto de destaque nessa avaliação são os fundamentos Legislação Trabalhista, Recrutamento e Seleçãoe Treinamento e Desenvolvimento, estes dois últimos, essenciais às empresas pesquisadas, que ofertam, em sua grande maioria, produtos de inovação tecnológica, e, normalmente, têm como principal ativo o capital intelectual. 


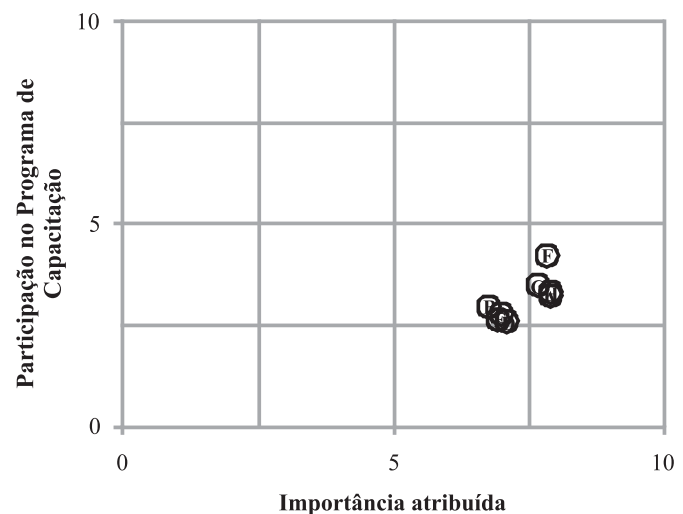

(A)

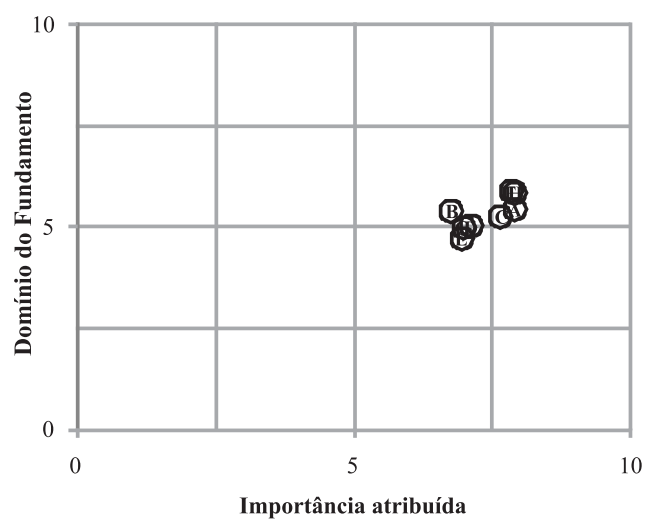

(B)

\section{Legenda:}
A Recrutamento e Seleção
E Programas de Incentivo
B Desenho de Cargos
F Treinamento e Desenvolvimento
C Avaliação de Desempenho
G Programas de Manutenção
D Administração de Salários
H Legislação Trabalhista

Figura 3: Avaliação da capacitação gerencial nos fundamentos de Recursos Humanos Fonte: Dados da pesquisa

Quanto ao domínio que os empresários declaram ter sobre os fundamentos, ele foi maior em Legislação Trabalhistae Treinamento e Desenvolvimento, ambos de grande importância relativa.Por outro lado, Programas de Manutenção, considerado um dos fundamentos de menor importância, foi avaliado também como o de menor domínio por parte dos empresários. Já quanto à presença dos fundamentos na capacitação gerencial, em todos os fundamentos a participação da incubadora na capacitação foi consideradaentre média e baixa, variando entre 2,5 e 5 (Figura 3A).

Em termos individuais, os fundamentos Desenho de Cargos, Programas de Incentivo, Programa de Manutenção e Administração de Salários foram considerados os menos presentes na capacitação. Assim como nos fundamentos de Marketing, verificou-se que em todos os fundamentos as situações são desfavoráveis tanto para as empresas quanto para as incubadoras, sendo pontos de carências os fundamentos com valores em destaques (Tabela 2). 
Tabela 2: Relação de equilíbrio nos fundamentos de recursos humanos

\begin{tabular}{|l|c|c|}
\hline \multirow{2}{*}{\multicolumn{1}{|c|}{ Fundamento }} & \multicolumn{2}{c|}{ Equilíbrio } \\
\cline { 2 - 3 } & $\begin{array}{c}\text { Importância } \\
\text { versus Domínio }\end{array}$ & $\begin{array}{c}\text { Importância versus } \\
\text { Capacitação }\end{array}$ \\
\hline Recrutamento e Seleção & 1,41 & $\underline{4,94}$ \\
\hline Desenho de Cargos & 1,41 & 3,99 \\
\hline Avaliação de Desempenho & $\underline{2,58}$ & 4,51 \\
\hline Administração de Salários & 2,17 & $\underline{4,77}$ \\
\hline Programas de Incentivo & $\underline{2,38}$ & 4,58 \\
\hline Treinamento e Desenvolvimento & 2,07 & 3,78 \\
\hline Programas de Manutenção & 2,18 & 4,48 \\
\hline Legislação Trabalhista & 2,03 & $\underline{4,84}$ \\
\hline Média & 2,18 & 4,49 \\
\hline
\end{tabular}

Fonte: Dados da pesquisa

Com base nos dados da Tabela 2, observou-se que os pontos de maior carência não são os mesmos para empresas (Importância versus Domínio) e incubadoras (Importância versus Capacitação), o que pode indicar a influência de outra(s) variável(eis) na proficiência do empresário em determinados pontos. Assim, o fundamento em que há maior desequilíbrio na relação entre importância e presença na capacitação pode não ser o de maior carência por parte das empresas.

\subsection{Fundamentos de Finanças}

A avaliação dos entrevistados em relação aos fundamentos de Finanças indica que elessão considerados de grande importância, já que a grande maioria possui notas distribuídas entre 7,5 e 10. Já em relação ao domínio nos mesmos fundamentos, foi considerado entre médio e alto - avaliações entre 5 e 7,5 (Figura 4). 


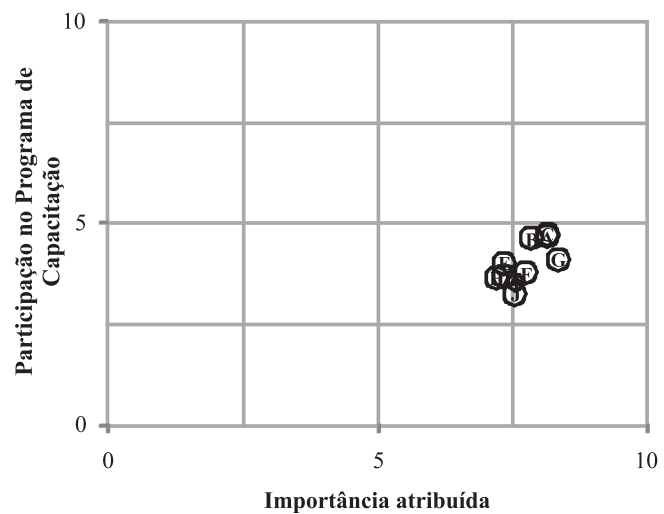

(A)

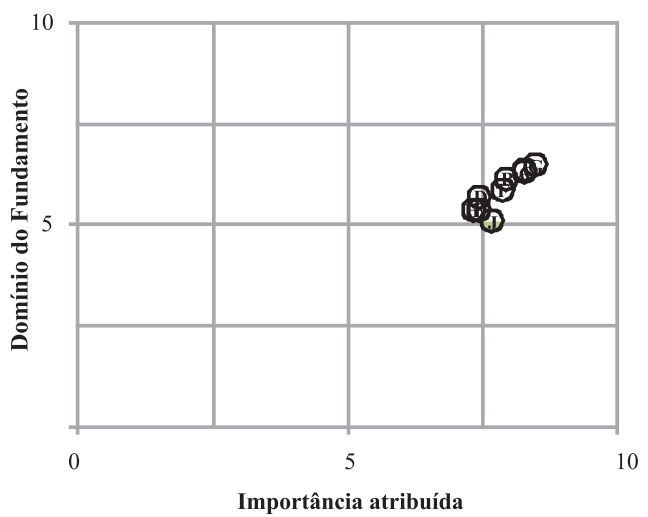

(B)

\section{Legenda:}
A Aspectos de Custos
F Administração do Capital de Giro
B Ponto de Equilíbrio
G Planejamento do Fluxo de Caixa
C Planejamento Financeiro
$\mathrm{H}$ Política de Financiamento
D Cálculos Financeiros
I Orçamento de Capital
E Análise das Demonstrações Financeiras
J Planejamento Tributário

Figura 4: Avaliação da capacitação gerencial nos fundamentos de Finanças Fonte: Dados da pesquisa

Dentre os fundamentos, os empresários atribuíram menor importância relativa à Análise das Demonstrações Financeiras, aos Cálculos Financeiros e à Política de Financiamento, estes dois últimos, podendo ser explicados pelo fato de a estrutura de capital das empresas ser constituída, em quase a sua totalidade, de capital próprio.

Por outro lado, parece ser explícita a preocupação dos empresários com variáveis que garantam a manutenção da saúde financeira da empresa em curto prazo e a alocação de custos, uma vez que os fundamentos considerados mais importantes foram Planejamento de Fluxo de Caixa, Planejamento Financeiro, Aspectos de Custos e Ponto de Equilíbrio. A perspectiva apresentada também se confirma quando observada a avaliação dos empresários em relação ao domínio nos fundamentos, sendo relativamente maior nos fundamentos de maior importância. 
Já em relação à presença dos fundamentos de finanças na capacitação gerencial, em todos os fundamentos, a participação da incubadora foi considerada entre média e baixa, variando entre 2,5 e 5, sendo pontos críticos o Planejamento Tributário, Orçamento de Capital, Cálculos Financeiros e Política de Financiamento (Figura 4A).

A tendência apresentada nos fundamentos de marketing e $\mathrm{RH}$ se fez presente também em finanças, área na qual em todos os fundamentos as situações são desfavoráveis tanto para as empresas quanto para as incubadoras (Tabela 3).

Tabela 3: Relação de equilíbrio nos fundamentos de finanças

\begin{tabular}{|l|c|c|}
\hline \multirow{2}{*}{\multicolumn{1}{|c|}{ Fundamento }} & \multicolumn{2}{c|}{ Equilíbrio } \\
\cline { 2 - 3 } & $\begin{array}{c}\text { Importância } \\
\text { versus Domínio }\end{array}$ & $\begin{array}{c}\text { Importância versus } \\
\text { Capacitação }\end{array}$ \\
\hline Aspectos de Custos & 1,91 & 3,69 \\
\hline Ponto de Equilíbrio & 1,70 & 3,40 \\
\hline Planejamento Financeiro & 2,01 & 3,61 \\
\hline Cálculos Financeiros & 1,67 & 3,83 \\
\hline Análise das Demonstrações Financeiras & 1,97 & $\underline{3,47}$ \\
\hline Administração do Capital de Giro & 1,88 & 4,16 \\
\hline Planejamento do Fluxo de Caixa & 1,88 & $\underline{4,44}$ \\
\hline Política de Financiamento & 1,79 & 3,70 \\
\hline Orçamento de Capital & $\underline{2,59}$ & 4,20 \\
\hline Planejamento Tributário & $\underline{2,48}$ & $\underline{4,65}$ \\
\hline Média & 1,99 & 3,91 \\
\hline
\end{tabular}

Fonte: Dados da pesquisa

Observou-se na Tabela 3 que os pontos de maior carência por parte dos empresários são Orçamento de Capital e Planejamento Tributário, este último, parecendo ser crítico, uma vez que, dentre os fundamentos de finanças, representa também a maior diferença entre importância e presença na capacitação. 


\subsection{Fundamentos de Operações}

A avaliação dos entrevistados em relação aos fundamentos de Operações indica que estes são considerados importantes, com notas distribuídas entre 5 e 10. Já em relação ao domínio nos mesmos fundamentos, foi considerado entre médio e baixo em Gestão da Qualidade e Gerenciamento de Estoques (avaliações entre 2,5 e 5), e entre médio e alto nos demais, com avaliações entre 5 e 7,5 (Figura 5).

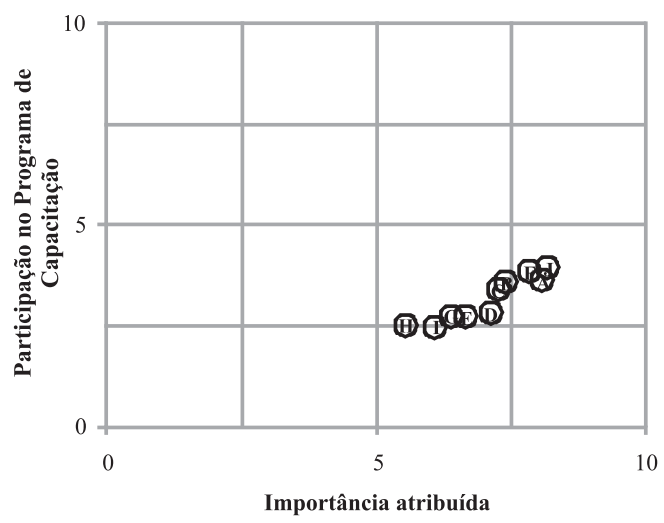

(A)

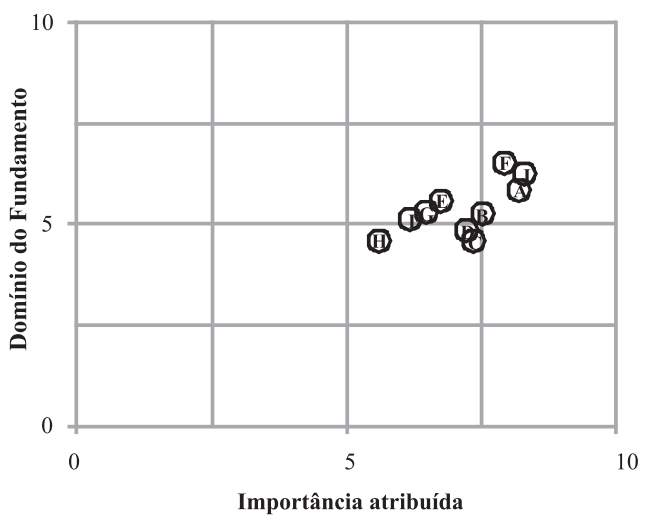

(B)

\section{Legenda:}
A Prioridade Competitiva
F Gerenciamento de Projetos
B Análise de Processos
G Gerenciamento da Cadeia de Suprimentos
C Gestão da Qualidade
$\mathrm{H}$ Gerenciamento de Estoques
D Previsão de Demanda
I Influência dos Fatores Ambientais
E Layout das Instalações
J Sistema de Informações Gerenciais

Figura 5: Avaliação da capacitação gerencial nos fundamentos de Operações Fonte: Dados da pesquisa

Dentre os fundamentos de operações, os empresários atribuíram maior importância relativa ao Gerenciamento de Projetos, Sistemas de Informações Gerenciais e Prioridade Competitiva, pontos nos quais os empresários declararam também ter maior domínio. Quanto à presença dos fundamentos na capacitação gerencial, a distribuição dos dados se mostrou relativamente homogênea, variando entre 2,5 e 5, fato este que indica ne- 
cessidade da incubadora em reforçar a capacitação em pontos aos quais os empresários atribuem maior importância relativa (Figura 5A).

Sobre o equilíbrio existente entre importância e domínio dos fundamentos, e importância e presença na capacitação, a tendência apresentada nas áreas anteriormente analisadas se fez presente também em Operações, área na qual em todos os fundamentos as situações são desfavoráveis tanto para as empresas quanto para as incubadoras (Tabela 4).

Tabela 4: Relação de equilíbrio nos fundamentos de operações

\begin{tabular}{|l|c|c|}
\hline \multirow{2}{*}{\multicolumn{1}{|c|}{ Fundamento }} & \multicolumn{2}{c|}{ Equilíbrio } \\
\cline { 2 - 3 } & $\begin{array}{c}\text { Importância } \\
\text { versus Domínio }\end{array}$ & $\begin{array}{c}\text { Importância versus } \\
\text { Capacitação }\end{array}$ \\
\hline Prioridade Competitiva & 2,24 & $\underline{4,68}$ \\
\hline Análise de Processos & 2,14 & 4,04 \\
\hline Gestão da Qualidade & $\underline{2,69}$ & 4,00 \\
\hline Previsão de Demanda & $\underline{2,37}$ & $\underline{4,51}$ \\
\hline Layout das Instalações & 1,08 & 4,13 \\
\hline Gerenciamento de Projetos & 1,35 & 4,25 \\
\hline Gerenciamento da Cadeia de Suprimentos & 1,03 & 3,86 \\
\hline Gerenciamento de Estoques & 0,88 & 3,17 \\
\hline Influência dos Fatores Ambientais & 1,00 & 3,85 \\
\hline Sistema de Informações Gerenciais & 2,06 & 4,51 \\
\hline Média & 1,68 & 4,10 \\
\hline
\end{tabular}

Fonte: Dados da pesquisa

Dentre os fundamentos de operações, podem ser considerados pontos críticos para os empresários a Gestão da Qualidade e a Previsão de Demanda. Este últimose caracteriza também por ser ponto de grande desequilíbrio em relação à participação da incubadora, assim como Prioridade Competitiva e Sistema de Informações Gerenciais, fundamento considerado de maior importância relativa.

\section{Considerações Finais e Recomendações}

Este trabalho teve como objetivo propor uma ferramenta de avaliação de programas de capacitação gerencial de Incubadoras de Empresas, a partir 
de um estudo de campo em 115 empreendimentos de base tecnológica. Ao considerar que esses empreendimentos nascentes buscam nas incubadoras não apenas elementos de infraestrutura e respaldo comercial, mas sim condições parase tornarem independentes, parece legítimo situar a capacitação gerencial oferecida pelas incubadoras em um eixo central nos programas de incubação. Dessa forma, identificar lacunas existentes entre a importância atribuída a um fundamento de gestão e o seu domínio por parte do empreendedor, bem como a presença desse fundamento no programa de capacitação, pode apontar a necessidade de ações por parte dos responsáveis pelos programas de capacitação.

O modelo matricial de avaliação dos fundamentos permitiu identificar quais pontos são considerados importantes pelos empresários, o domínio em cada um deles e como ele, empresário, avalia a efetividade da incubadora na capacitação gerencial. A análise individual nas áreas de gestão indica que maior importância atribuída às áreas de finanças e marketing, esta última, área também na qual os empresários avaliaram de maneira mais positiva a efetividade da capacitação oferecida pela incubadora.

Em relação à análise de equilíbrio entre importância e domínio dos fundamentos por parte dos empresários e entre importância e efetividade ou presença dos fundamentos na capacitação gerencial, verificou-se a existência de lacunas a serem supridas tanto pelos empresários quanto pelas incubadoras. Em todos os fundamentos contemplados nesse trabalho verificaram-se situações desfavoráveis, uma vez que os empresários avaliaram seus domínios inferiores à importância de cada fundamento, da mesma forma que a efetividade da capacitação oferecida pela incubadora.

Embora simplificado, o uso de modelos matriciais pode representar para as incubadoras um importante ferramental na análise do processo de capacitação, uma vez que possibilita identificar e mensurarsua participação na formação gerencial dos empresários, sob a perspectiva desses últimos. Ademais, revela também os pontos aos quais os empresários atribuem maior importância e, por consequência, necessitam ser reforçados.

Como é praxe em estudos de natureza exploratória, o uso de matrizes na avaliação da capacitação gerencial é apenas uma tentativa de se conhecer melhor a forma como os empresários avaliam a participação da incubadora, bem como seus domínios em cada fundamento. Assim, recomenda-se que novos estudos sejam realizados, a fim de incrementar um modelo desta natureza, tanto em aspectos quantitativos quanto qualitativos, na prospecção de novos fundamentos que, por ventura, não tenham sido contemplados. 
Por fim, vale ressaltar que os dados obtidos refletem a realidade encontrada nas empresas localizadas em Minas Gerais. Dessa forma, qualquer tentativa de generalização dos resultados poderia apresentar viés, uma vez que vários dos fatores presentes no processo de incubação são peculiares da realidadepesquisada.

\section{Proposition of Evaluating Management Training in Technology-Based Incubators by a Matrix Model}

\section{Abstract}

The management training is one element of the incubation process that has been highlighted because of its importance in the entrepreneurs' development as managers. This article aims to propose an evaluation tool for Incubators' management training programs, developed based on a research in 14 incubators and 115 technology-based enterprises. The four main management areas (i.e. Marketing, Human Resources, Finance and Operations) were used find opportunity for improvements in training programs. The tool is composed by two dimensions: (a) one compares the domain that the entrepreneur believes to have in each discipline and the relative importance of this discipline in your business, (b) another dimension compares this importance attached by the entrepreneur and the content of training program offered by the incubator. The results show, respectively, the gaps in the knowledge that entrepreneurs think they have and which points can be better exploited by the incubator management training. The field study revealed that Marketing and Finance are considered more important by entrepreneurs and more covered in training programs. Moreover, it was found that there are gaps between importance given by entrepreneurs and the effectiveness of the incubator in some elements, which suggests the need to reassess the programs of managerial training.

Key words: Managerial training. Technology-based incubators. Evaluating model.

\section{Referências}

ANPROTEC - Associação Nacional de Entidades Promotoras de Empreendimentos de Tecnologia Avançada. Panorama 2007. Disponível em: <http:// mercadoetico.terra. com.br/noticias.view.php?id=3194>. Acesso em: 10 ago. 2008. 
Glossário dinâmico de termos na área de tecnópolis, Parques Tecnológicos e Incubadoras de Empresas. Brasília: ANPROTEC, 2002. Disponível em: <http://redeincubar.anprotec.org.br:8280/portal/ montarSecaoPublicacaoAnprotec.do >. Acesso em: 27 jan. 2006.

; SEBRAE. Planejamento e implantação de incubadoras de empresas. Brasília: Anprotec, 2002.

ARANHA, J. A. S. et al. Modelo de gestão para incubadoras de empresas: implementação do modelo de gestão para incubadoras de empresas. Rio de Janeiro: Rede de Tecnologia do Rio de Janeiro, 2002.

ARAÚJO, L. C. G. de. Gestão de pessoas: estratégias e integração organizacional. São Paulo: Atlas, 2006.

ASSAF NETO, A. Finanças corporativas e valor. São Paulo: Atlas, 2003.

BAÊTA, A. M. C. As incubadoras de empresas de base tecnológica: uma nova prática organizacional para a inovação. (dissertação), COPPE/UFRJ, Rio de Janeiro, 1997.

BAKOUROS, Y. L.; MARDAS, D. C.; VARSAKELIS, N. C. Science park, a high tech fantasy? An analysis of the science parks of Greece. Technovation, n. 22, 123-128, 2002.

BOLLINGTOFT, A.; ULHOI, J. P. The networked business incubatorleveraging entrepreneurial agency. Journal of Business Venturing, v. 20, p. 265-290, 2005.

CHAN, K. F.; LAU, T. Assessing technology incubator programs in the science park: the good, the bad and the ugly. Technovation, v. 25, p. 1215-1228, 2005.

CHIAVENATO, I. Gestão de pessoas: o novo papel dos recursos humanos nas organizações. Rio de Janeiro: Campus, 1999.

CORRÊA, H. L.; CORRÊA, C. A. Administração da produção e operações: manufatura e serviços: uma abordagem estratégica. 2. ed. São Paulo: Atlas, 2007.

CZINKOTA, M. R. et al. Marketing: as melhores práticas. Porto Alegre: Bookman, 2002. 
DALRYMPLE, Douglas J.; PARSONS, Leonard J. Introdução à administração de Marketing. Rio de Janeiro: LTC, 2003.

GAITHER, N; FRAZIER, G. Administração da produção e operações. 8. ed. São Paulo: Pioneira Thomson, 2001.

GITMAN, L. J. Princípios de administração financeira. 2. ed. Porto Alegre: Bookman, 2001.

GRIMALDI, R.; GRANDI, A. Business incubators and new venture creation: an assessment of incubating models. Technovation, v. 25, p. 111-121, 2005.

HACKETT, S.; DILTS, D.A Systematic Review of Business Incubation Research. Journal of Technology Transfer, v. 29, p. 55-82, 2004.

KOTLER, P.; ARMSTRONG, G. Princípios de marketing. 12. ed. São Paulo: Pearson Prentice Hall, 2008.

KOTLER, P.; KELLER, K. L. Administração de marketing. 12. ed. São Paulo: Pearson Prentice Hall, 2005.

KWASNICKA, E. L. Introdução à Administração. São Paulo: Atlas, 2004.

LACOMBE, F. Recursos Humanos: princípios e tendências. São Paulo: Saraiva, 2006.

LEMOS, M. V. O papel das incubadoras de empresas na superação das principais dificuldades das pequenas empresas de base tecnológica. 1998. 100f. Dissertação (Mestrado em Engenharia de Produção) - COPPE/ UFRJ, Rio de Janeiro.

MACUlAN, A. M. D. As Pequenas Empresas de Base Tecnológica. COPPE/UFRJ, Rio de Janeiro, 1996a.

. Estratégia Tecnológica de Micro-empresas localizadas numa Incubadora. In: SIMPÓSIO DE GESTÃO DA INOVAÇÃO TECNOLÓGICA, 19., v. 2, p. 357-369, São Paulo. Anais... São Paulo, out. 1996b.

. Incubação, capacidade de inovação e aprendizado organizacional das empresas de base tecnológica. In: SEMINÁRIO INTERNACIONAL EMPREENDEDORISMO, PEQUENAS EMPRESAS E DESENVOLVIMENTO LOCAL. Rio de Janeiro. Anais... Rio de Janeiro, 2004. 
MYLLYNIEMI, T. et al. The growth of new technology-based companies. Helsink: Sitra, 1990.

NBIA - National Business Incubator Association. NBIA online. Disponível em: <www.nbia.org>. Acesso em: 26 jan. 2006.

O'NEAL, T. Evolving a Successful University-Based Incubator: Lessons Learned from the UCF Technology Incubator. Engineering ManagementJournal, v. 17, n. 3, 2005.

RMI - Rede Mineira de Inovação. Catálogo das Incubadoras de Minas Gerais. Belo Horizonte: RMI, 2005.

ROSS, S. A.; WESTERFIELD, R. W.; JAFFE, J. F. Administração financeira: corporate finance. 2. ed., São Paulo: Atlas, 2002.

SANTOS, S. A.; PEREIRA, H. J. Aglomerado de empresas de alta tecnologia: uma experiência de entrepreneurship. Revista de Administração, v. 24, n. 1, p. 67-75, jan./mar. 1989.

SELLTIZ, C. et al. Métodos de pesquisa nas relações sociais. São Paulo: Helder, 1967.

SILVA, C. M. de S. Inovação e cooperação: o estado das artes no Brasil.

Revista do BNDES, v. 7, n. 13, p. 65-88, 2000.

SLACK, N.; CHAMBERS, S.; JOHNSTON, R. Administração da produção. 2. ed. São Paulo: Atlas, 2002.

SOUZA, J. D. Gestão de pessoas: modelo, processos, tendências e perspectivas. São Paulo: Atlas, 2002.

STEVENSON, W. J. Administração das operações de produção. 6. ed. Rio de Janeiro: LTC, 2001.

STONE, H.; SIDEL, J. L. Sensory Evaluation Practices. London: Academic Press Inc., 1993.

URDAN, F. T.; URDAN, A. T. Gestão do composto de marketing. São Paulo: Atlas, 2006. 
VALÉRIO, M. V. Marketing orientado para resultado. In: NETTO, A. V. Gestão das Pequenas e Médias Empresas de Base Tecnológica. Brasília, DF: Minha Editora: SEBRAE, 2006.

VEDOVELLO, C.; FIGUEIREDO, P. N. Incubadora de inovação: que nova espécie é essa? RAE-eletrônica, v. 4, n. 1, art. 10, jan./jul, 2005.

WESTON, J. F.; BRIGHAM, E. F. Fundamentos de administração financeira. 10. ed. São Paulo: Pearson Makron Books, 2004. 